\title{
NUEVAS PATOLOGIAS EN ESPARRAGUERAS DE SANTA FE
}

\author{
Maumary, R. ${ }^{1}$, LenZI, D. ${ }^{1}$, SILlon, M. ${ }^{1} \&$ RISTA, L. ${ }^{1}$
}

\begin{abstract}
RESUMEN
En el cinturón hortícola santafesino, el cultivo del espárrago constituye, por su perennidad, tipo de manejo y valor económico, una alternativa productiva importante.

Productores hortícolas de Recreo (Santa Fe) observaron procesos de atizonamiento y defoliación en forma anticipada, con pérdida de calidad de turiones.

El objetivo del trabajo fue establecer la etiología de los síntomas observados, para lo cual se procedió al aislamiento e identificación de los microorganismos siguiendo técnicas fitopatológicas de rutina. Se confirmó la presencia de dos patógenos como responsables del problema sanitario detectado sobre el cultivo. Los hongos presentes corresponden al género Stemphylium sp., causante de la mancha púrpura o estenfiliosis; y Cercospora asparagi responsable del tizón del espárrago, siendo las primeras citas de estos patógenos sobre espárragos en Santa Fe.
\end{abstract}

Palabras clave: Asparagus officinalis, Cercospora spp., Stemphyllium spp.

\section{SUMMARY}

\section{New pathology in asparagus crops in Santa Fe.}

In vegetable production area around Santa Fe city asparagus is an important perennial crop with high economic value. Vegetable farmers have observed anticipated defoliation and blight symptoms, with quality losses in turions.

Our objective was athiology determination according to the observed symptons. Therefore, the isolation and identification of pathogens was performed following routine techniques.

Two pathogens were identified: Stemphylium spp., which causes purple spot disease and Cercospora asparagi, who is related to asparagus blight. It has been the first occasion that these pathogens were identified in Santa Fe.

Key words: Asparagus officinalis, Cercospora spp., Stemphyllium spp.

1.- Laboratorio de Fitopatología. Facultad de Ciencias Agrarias, Universidad Nacional del Litoral.

Kreder 2805. (3080) Esperanza, provincia de Santa Fe. Telefax: (03496) 426400.

E-mail: lrista@fca.unl.edu.ar

Manuscrito recibido el 24 de octubre de 2001 y aceptado para su publicación el 23 de julio de 2002. 